\section{References}

1. Cairns RA, Mak TW. Oncogenic isocitrate dehydrogenase mutations: mechanisms, models, and clinical opportunities. Cancer Discov. 2013;3:730-41.

2. Ward PS, Patel J, Wise DR, Abdel-Wahab O, Bennett BD, Coller HA, et al. The common feature of leukemia-associated IDH1 and IDH2 mutations is a neomorphic enzyme activity converting alphaketoglutarate to 2-hydroxyglutarate. Cancer Cell. 2010;17:225-34.

3. Dang L, White DW, Gross S, Bennett BD, Bittinger MA, Driggers $\mathrm{EM}$, et al. Cancer-associated IDH1 mutations produce 2hydroxyglutarate. Nature. 2009;462:739-44.

4. Gross S, Cairns RA, Minden MD, Driggers EM, Bittinger MA, Jang HG, et al. Cancer-associated metabolite 2-hydroxyglutarate accumulates in acute myelogenous leukemia with isocitrate dehydrogenase 1 and 2 mutations. J Exp Med. 2010;207:339-44.

5. Figueroa ME, Abdel-Wahab O, Lu C, Ward PS, Patel J, Shih A, et al. Leukemic IDH1 and IDH2 mutations result in a hypermethylation phenotype, disrupt TET2 function, and impair hematopoietic differentiation. Cancer Cell. 2010;18:553-67.

6. Schnittger S, Haferlach C, Ulke M, Alpermann T, Kern W, Haferlach T. IDH1 mutations are detected in $6.6 \%$ of 1414 AML patients and are associated with intermediate risk karyotype and unfavorable prognosis in adults younger than 60 years and unmutated NPM1 status. Blood. 2010;116:5486-96.

7. Paschka P, Schlenk RF, Gaidzik VI, Habdank M, Kronke J, Bullinger L, et al. IDH1 and IDH2 mutations are frequent genetic alterations in acute myeloid leukemia and confer adverse prognosis in cytogenetically normal acute myeloid leukemia with NPM1 mutation without FLT3 internal tandem duplication. J Clin Oncol. 2010;28:3636-43.

8. Capper D, Zentgraf H, Balss J, Hartmann C, von Deimling A. Monoclonal antibody specific for IDH1 R132H mutation. Acta Neuropathol. 2009;118:599-601.

9. Falini B, Mecucci C, Tiacci E, Alcalay M, Rosati R, Pasqualucci $\mathrm{L}$, et al. Cytoplasmic nucleophosmin in acute myelogenous leukemia with a normal karyotype. N Engl J Med. 2005;352:254-66.

10. Falini B, Martelli MP, Bolli N, Bonasso R, Ghia E, Pallotta MT, et al. Immunohistochemistry predicts nucleophosmin (NPM) mutations in acute myeloid leukemia. Blood. 2006;108:1999-2005.

11. Meggendorfer M, Cappelli LV, Walter W, Haferlach C, Kern W, Falini B, et al. IDH1R132, IDH2R140 and IDH2R172 in AML: different genetic landscapes correlate with outcome and may influence targeted treatment strategies. Leukemia. 2018;32:1249-53.

12. Lindsley RC, Mar BG, Mazzola E, Grauman PV, Shareef S, Allen SL, et al. Acute myeloid leukemia ontogeny is defined by distinct somatic mutations. Blood. 2015;125:1367-76.

13. Papaemmanuil E, Gerstung M, Bullinger L, Gaidzik VI, Paschka $\mathrm{P}$, Roberts ND, et al. Genomic classification and prognosis in acute myeloid leukemia. N Engl J Med. 2016;374:2209-21.

14. DiNardo CD, Stein EM, de Botton S, Roboz GJ, Altman JK, Mims AS, et al. Durable remissions with ivosidenib in IDH1mutated relapsed or refractory AML. $\mathrm{N}$ Engl $\mathrm{J}$ Med 2018;378:2386-98.

Lymphoma

\title{
Dose-adjusted EPOCH plus rituximab improves the clinical outcome of young patients affected by double expressor diffuse large B-cell lymphoma
}

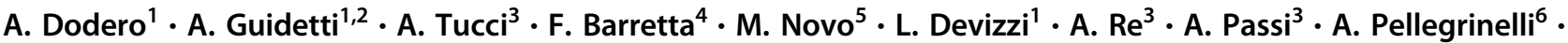 \\ G. Pruneri ${ }^{2,6} \cdot$ R. Miceli ${ }^{4}$ - A. Testi ${ }^{6} \cdot$ M. Pennisi ${ }^{1}$ - M. C. Di Chio ${ }^{1}$ - P. Matteucci ${ }^{1}$ - C. Carniti ${ }^{1}$ - F. Facchetti ${ }^{7}$ - G. Rossi ${ }^{3}$. \\ P. Corradini $\mathbb{D}^{1,2}$
}

Received: 17 July 2018 / Revised: 5 October 2018 / Accepted: 6 November 2018 / Published online: 10 January 2019

(c) The Author(s) 2019. This article is published with open access

These authors contributed equally: A. Dodero, A. Guidetti

Supplementary information The online version of this article (https:// doi.org/10.1038/s41375-018-0320-9) contains supplementary material, which is available to authorized users.

A. Guidetti

anna.guidetti@istitutotumori.mi.it

anna.guidetti@unimi.it

1 Department of Hematology, Fondazione IRCCS Istituto Nazionale dei Tumori, Milano, Italy

2 Department of Oncology and Hemato-Oncology, University of Milano, Milano, Italy

3 Department of Hematology, Azienda Ospedaliera Spedali Civili di Brescia, Brescia, Italy

\section{To the Editor:}

Diffuse large B-cell lymphoma (DLBCL) is a heterogeneous disease. Patients carrying the double expression of

4 Department of Clinical Epidemiology and Trial Organization, Fondazione IRCCS Istituto Nazionale dei Tumori, Milano, Italy

5 Department of Hematology, Azienda Ospedaliero Universitaria Citta' della Salute e della Scienza di Torino, Torino, Italy

6 Department of Pathology, Fondazione IRCCS Istituto Nazionale dei Tumori, Milano, Italy

7 Department of Pathology, Azienda Ospedaliera Spedali Civili di Brescia, Brescia, Italy 
MYC and BCL2 (double expressor, DE) with or without concomitant translocations of MYC and BCL2, and/or BCL6 genes have a dismal prognosis. In patients affected by DE DLBCL without translocations, the 5-year overall survival (OS) is $\sim 40 \%$ with R-CHOP. In high grade B-cell lymphomas [i.e., double hit (DH) or triple hit (TH) lymphomas], the median OS is $\sim 12$ months [1-6]. Therefore, no standard therapy for these disease entities exists, and their optimal treatment represents an urgent unmet clinical need.

At our Institution, the DA-EPOCH-R has been adopted for all DE DLBCL patients since 2013. The present study compared the outcome of patients treated in a similar period at three different Italian institutions with DA-EPOCH-R and $\mathrm{R}-\mathrm{CHOP}$. We estimated the propensity score (PS) as a balancing score to account for the biases consistent with a non-random treatment assignment. The treatment effect in the multivariable Cox models was estimated using an inverse-probability-of-treatment-weight (IPTW) based on PS [7].

Diagnosis was performed according to the WHO classification and was reviewed by two expert hematopathologists [patients with primary mediastinal and human immunodeficiency virus-associated lymphomas or central nervous system (CNS) disease were excluded]. Immunohistochemistry analysis and FISH were performed in all patients and are detailed in Supplementary Appendix. The cut-off levels for positivity for MYC and BCL2 were $\geq 40 \%$ and $\geq 50 \%$, respectively [8]. In this analysis, we included stages II-IV or stage I disease with an International Prognostic Index (IPI) score $\geq 1$ or bulky disease. The Ethical Committees of participating centers approved the study (INT55/17). Written informed consent was obtained from all patients.

The DA-EPOCH-R regimen was administered as previously described every 21 days for 6 cycles and doseadjustment was based on blood counts between cycles [9]. R-CHOP was administered every 21 days. CNS prophylaxis with lumbar puncture or intravenous methotrexate was administered according to institutional guidelines. Disease assessment during the study was described in Supplementary Appendix.

The primary objective of the study was to compare the 2year PFS and OS in the DA-EPOCH-R and R-CHOP cohorts. Secondary objectives included comparisons of survival according to different prognostic factors (age, stage, IPI, cell of origin and cytogenetic characterization). Statistical Methods are summarized in Supplementary Appendix.

A total of 114 consecutive patients were identified for the study. Table 1 summarizes the main clinical and biological characteristics of the patients. Fifty-one patients received DA-EPOCH-R between October 2013 and October 2017 while 63 patients were treated with R-CHOP between
Table 1 Clinical and biological characteristics

\begin{tabular}{|c|c|c|c|c|}
\hline Variable & $\begin{array}{l}\text { ALL } \\
N=114\end{array}$ & $\begin{array}{l}\text { DA-EPOCH-R } \\
N=51\end{array}$ & $\begin{array}{l}\text { R-CHOP } \\
N=63\end{array}$ & SMD before/after \\
\hline \multicolumn{5}{|l|}{ Age } \\
\hline Median & 62 years & 58 years & 65 years & $0.296 /<0.001$ \\
\hline Range & $29-81$ & $29-79$ & $36-81$ & \\
\hline Age $>65$ years & $43(38 \%)$ & $14(27 \%)$ & $29(46 \%)$ & \\
\hline \multicolumn{5}{|l|}{ Sex } \\
\hline Male & $70(62 \%)$ & $32(63 \%)$ & $38(60 \%)$ & $0.049 / 0.018$ \\
\hline Female & $44(38 \%)$ & $19(37 \%)$ & $25(40 \%)$ & \\
\hline \multicolumn{5}{|l|}{ Histology } \\
\hline DLBCL & $106(93 \%)$ & $47(92 \%)$ & $59(94 \%)$ & \\
\hline Transformed & $8(7 \%)$ & $4(8 \%)$ & $4(6 \%)$ & - \\
\hline \multicolumn{5}{|l|}{ Stage } \\
\hline I-II & $28(25 \%)$ & $8(16 \%)$ & $20(32 \%)$ & $0.850 / 0.079$ \\
\hline III-IV & $86(75 \%)$ & $43(84 \%)$ & $43(68 \%)$ & \\
\hline \multicolumn{5}{|l|}{ IPI } \\
\hline $1-2$ & $62(54 \%)$ & $24(47 \%)$ & $38(60 \%)$ & $0.332 / 0.101$ \\
\hline $3-5$ & $52(46 \%)$ & $27(53 \%)$ & $25(40 \%)$ & \\
\hline \multicolumn{5}{|l|}{ BM involvement } \\
\hline Yes & $22(19 \%)$ & $16(32 \%)$ & $6(10 \%)$ & $0.552 / 0.421$ \\
\hline No & $92(81 \%)$ & $35(68 \%)$ & $57(90 \%)$ & \\
\hline \multicolumn{5}{|l|}{ Extranodal involvement ${ }^{a}$} \\
\hline Yes & $69(60 \%)$ & $46(90 \%)$ & $23(36 \%)$ & - \\
\hline No & $45(40 \%)$ & $5(10 \%)$ & $40(64 \%)$ & \\
\hline \multicolumn{5}{|l|}{ CNS involvement } \\
\hline Leptomeningeal & $3(3 \%)$ & $2(4 \%)$ & $1(1 \%)$ & - \\
\hline \multicolumn{5}{|l|}{ Cytogenetic abnormalities } \\
\hline DE-only & $58(51 \%)$ & $18(35 \%)$ & $40(63 \%)$ & $0.749 / 0.119$ \\
\hline DE with SH & $29(25 \%)$ & $16(31 \%)$ & $13(21 \%)$ & \\
\hline DE with $\mathrm{DH} / \mathrm{TH}$ & $10(9 \%)$ & $8(16 \%)$ & $2(3 \%)$ & \\
\hline DE with atypical DH & $15(13 \%)$ & $9(18 \%)$ & $6(10 \%)$ & \\
\hline Missing & $2(2 \%)$ & $0(0 \%)$ & $2(3 \%)$ & \\
\hline \multicolumn{5}{|l|}{ FISH rearrangements } \\
\hline MYC R & $7(6 \%)$ & $5(10 \%)$ & & - \\
\hline BCL2 R & $8(7 \%)$ & $5(10 \%)$ & $2(3 \%)$ & \\
\hline BCL6 R & $14(12 \%)$ & $6(12 \%)$ & $3(5 \%)$ & \\
\hline MYC R/BCL2 R & $5(4 \%)$ & $4(7 \%)$ & $8(13 \%)$ & \\
\hline MYC R/BCL6 R & $2(2 \%)$ & $2(4 \%)$ & $1(2 \%)$ & \\
\hline MYC R/BCL2 R/BCL6 R & $3(3 \%)$ & $2(4 \%)$ & $0(0 \%)$ & \\
\hline Cell of origin (Hans) & & & & $0.334 / 0.049$ \\
\hline GCB & $42(37 \%)$ & $22(43 \%)$ & $20(31 \%)$ & \\
\hline Non GCB & $57(50 \%)$ & $25(49 \%)$ & $32(51 \%)$ & \\
\hline Not evaluable & $15(13 \%)$ & $4(8 \%)$ & $11(18 \%)$ & \\
\hline
\end{tabular}

$S M D$ Standardized mean difference calculated before and after weighting, $D L B C L$ diffuse large B-cell lymphomas, $B M$ bone marrow, FISH fluorescence in situ hybridization, $D E$ double expressor, $S H$ single-hit, $D H$ double hit, $T H$ triple hit, $R$ rearrangements, $G C B$ germinal center B-cell lymphomas

${ }^{a}$ At least one extranodal involvement

October 2009 and October 2017. Cohorts were well balanced across all covariates included in the PS model after IPTW adjustment as indicated by the standardized mean difference (SMD) values calculated after weighting $(<0.1)$. The overall response rates were $80 \%$ [CR, $n=37(73 \%)$; $\mathrm{PR}, n=4]$, and $76 \%$ [CR, $n=44$ (71\%); PR, $n=4]$ following DA-EPOCH-R and R-CHOP, respectively.

Patients in the R-CHOP group received less CNS prophylaxis compared to those treated with DA-EPOCH-R 
(30\% vs 96\%). In particular, since 2016 patients in the DA-EPOCH-R group [23 of 51 (45\%)] received four lumbar punctures with methotrexate, cytarabine, and dexamethasone followed by intravenous Methotrexate ( $3.5 \mathrm{~g} / \mathrm{ms}$, for 2 courses) whereas all other patients received triple intrathecal prophylaxis only. CNS relapses following DA-EPOCH-R and R-CHOP were observed in one and three patients, respectively. Consolidative radiotherapy was administered in $21 \%$ and $35 \%$ of the patients in the DAEPOCH-R and R-CHOP cohorts, respectively. Death occurred in $6(12 \%)$ patients receiving DA-EPOCH-R [PD $(n=4)$, pneumonia $(n=1)$, suicide $(n=1)]$, and in 22 $(35 \%)$ R-CHOP patients [PD $(n=20)$, toxicity $(n=2)]$, respectively.

DA-EPOCH-R dose escalation was feasible in most patients aged $\leq 65$ years with $73 \%$ of the patients being escalated to the 3rd dose level or above (Supplementary Figure 1). In contrast, the majority of the elderly patients ( $\geq 65$ years) received therapy at level 1 (11 out of $14,78 \%$ ) due to comorbidities and toxicities. Supplementary Table 1 lists the primary toxicities observed during DA-EPOCH-R. Therapy discontinuation due to adverse events occurred in two patients per arm [DA-EPOCH-R: pneumonia (Grade 5) and infection (alive in CR); R-CHOP: toxicity (Grade 5, $n=2)]$.

Median follow-ups were 20 and 49 months in the DAEPOCH-R and R-CHOP group, respectively. The 2-year PFS and OS, before IPTW adjustment, were 62\% (95\% CI: 45-84\%) and 85\% (95\% CI: 74-98\%) following DAEPOCH-R and 54\% (95\% CI: 43-69\%) and 70\% (95\% CI: 60-83\%) following R-CHOP, respectively. After weighting no significant statistical differences in the 2-year PFS $(57 \%$ vs $51 \%, p=0.198)$ or OS (90\% vs $67 \%, p=0.07)$ were observed following DA-EPOCH-R or R-CHOP, respectively (Fig. 1a, b).

We then used an IPTW based on PS to estimate the potential impact of the two regimens on age $(\leq 65$ vs $>65)$, disease stage (limited vs advanced), IPI [low risk (IPI 1-2) vs high risk (IPI 3-5)], non-Germinal Center B-cell like subgroup. In this analysis, age emerged as a clinically relevant variable. In fact, patients aged $<65$ years treated with DA-EPOCH-R exhibited a better PFS [82\% (95\% CI: 66-100\%) vs $43 \%$ (95\% CI: $26-73 \%), p=0.020]$ and a better OS [90\% (95\% CI: $74-100 \%)$ vs $62 \%$ (95\% CI: $43-$ $88 \%), p=0.042$ ] compared to those receiving $\mathrm{R}-\mathrm{CHOP}$ (Fig. 1c, d). We did not observe any significant advantage for any other subgroup.

Analyses with IPTW adjustment were also performed on the entire cohort according to treatment (DA-EPOCH-R vs $\mathrm{R}-\mathrm{CHOP}$ ) and absence or presence of genetic lesions (DEonly including patients lacking cytogenetic alterations, vs "other" including single-hit, DH/TH or atypical DH patients [10]). The subgroup of patients with any type of cytogenetic abnormality treated with R-CHOP, had a worse 2-year PFS compared to the other subgroups (41\% vs $59 \%, p<0.001)$ (Fig. 1e).

Survival analysis of the entire study population revealed similar OS and PFS for R-CHOP and DA-EPOCH-R patients. In contrast, patients younger than 65 years achieved a 2-year PFS of $82 \%$, which was significantly better than the PFS observed with R-CHOP. Most of the patients older than 65 years were treated with the first dose level compared to the group of younger patients who generally received level 3 or above (73\% of cases) (Supplementary Figure 1). This suggests that the efficacy of the treatment in the younger population might be ascribed to the higher cumulative dose of chemotherapy received and not only to the continuous infusion of the drugs.

A possible counfounding factor in this study relates to CNS prophylaxis which varied over time. Biomarkers influencing CNS relapse risk, independently from clinical risk model (CNS-IPI), are in fact a recent acquisition. However, the observed rate of CNS relapse is in line with previous publications describing a risk of $13 \%$ and $9.7 \%$ at 2 years in patients affected by $\mathrm{DH} / \mathrm{TH}$ and $\mathrm{DE}$ lymphomas, respectively $[11,12]$.

In this retrospective study, possible biases between $\mathrm{R}$ CHOP and DA-EPOCH-R cohorts were balanced using stabilized IPTW based on the PS in all survival analyses. Our results indicate the potential role of DA-EPOCH-R in the treatment of DE DLBCL patients mainly because of three relevant observations: (1) treatment with DA-EPOCH$\mathrm{R}$ compared to R-CHOP was associated with a significant improvement of PFS and OS in patients younger than 65 years; (2) all patients with genetic abnormalities (single translocations, atypical $\mathrm{DH}$, and $\mathrm{DH} / \mathrm{TH}$ ) had better PFS with DA-EPOCH-R; and (3) intensification with DAEPOCH-R was feasible and safe in young patients.

It is clear that the optimal chemo-immunotherapy for patients affected by DE DLBCL with or without gene rearrangements is still a matter of debate. However, the results observed with $\mathrm{R}-\mathrm{CHOP}$ are considered unsatisfactory, and most published studies using more intensive regimens were retrospective and limited to the $\mathrm{DH} / \mathrm{TH}$ subgroup [13, 14]. To our knowledge, this is the first report analyzing the survival of a consecutive cohort of genetically characterized DE patients treated with DA-EPOCH-R. In addition to DH/TH lymphomas, $30-50 \%$ of patients in both cohorts exhibited single translocations or were atypical DH. We observed that DE patients carrying any genetic abnormality had a poor PFS when treated with R-CHOP while they experienced a significantly better outcome with DA-EPOCH-R. Separate survival analyses according to single cytogenetic alteration or combining age and cytogenetic alterations were not possible because of the limited number of patients in each subgroup. 
A

PFS

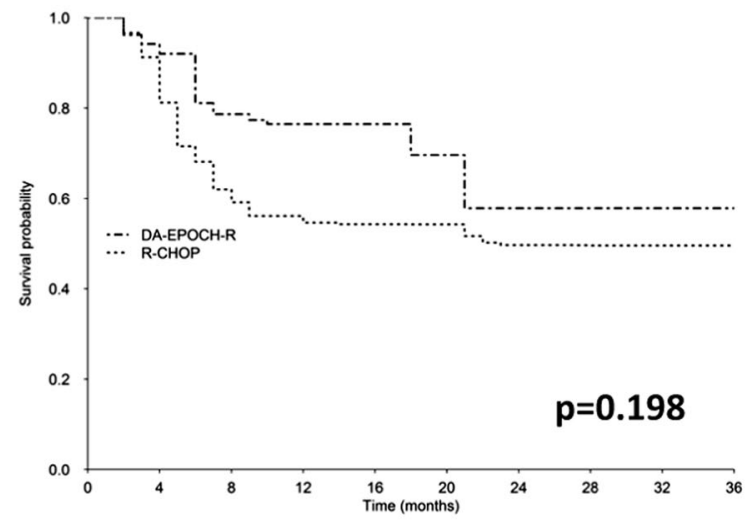

$\begin{array}{rrrrrrrrrrr}\text { DA.EPOCH.R } & 51 & 45 & 31 & 23 & 19 & 10 & 8 & 4 & 2 & 2 \\ \text { R.CHOP } & 63 & 60 & 46 & 39 & 34 & 30 & 26 & 24 & 22 & 19\end{array}$

C

PFS

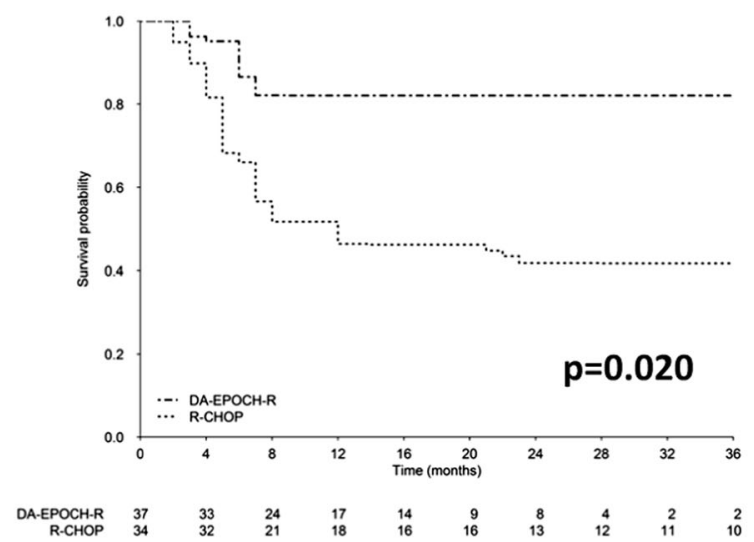

B

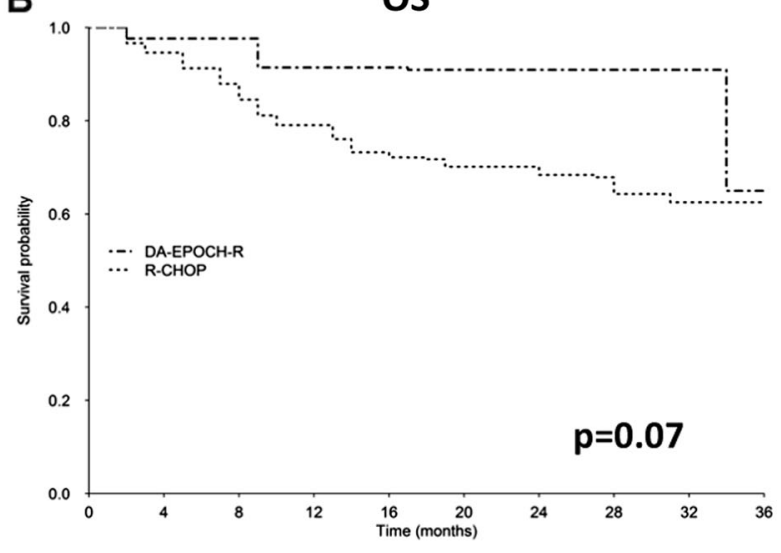

$\begin{array}{rllllllllll}\text { DA-EPOCH-R } & 51 & 47 & 39 & 29 & 24 & 12 & 10 & 6 & 4 & 2 \\ \text { R-CHOP } & 63 & 61 & 58 & 52 & 47 & 38 & 37 & 34 & 31 & 28\end{array}$

D
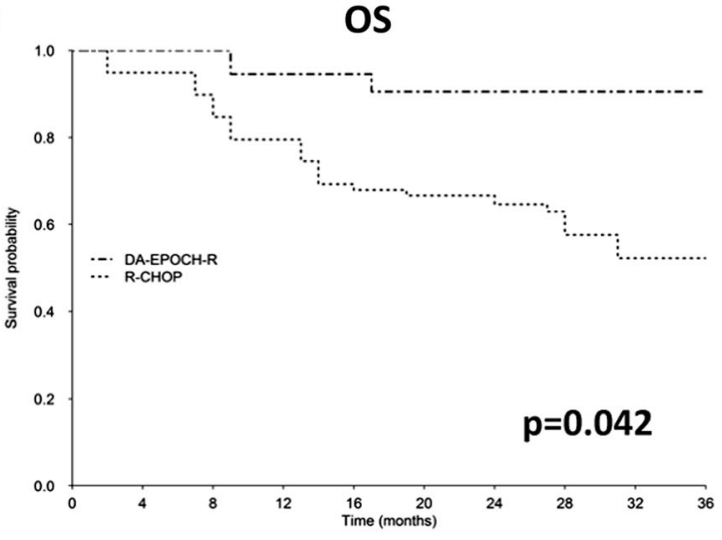

$\begin{array}{rrrrrrrrrrr}\text { DA.EPOCH.R } & 37 & 35 & 30 & 20 & 16 & 9 & 8 & 4 & 2 & 2 \\ \text { R.CHOP } & 34 & 33 & 31 & 27 & 25 & 22 & 22 & 19 & 17 & 16\end{array}$

PFS

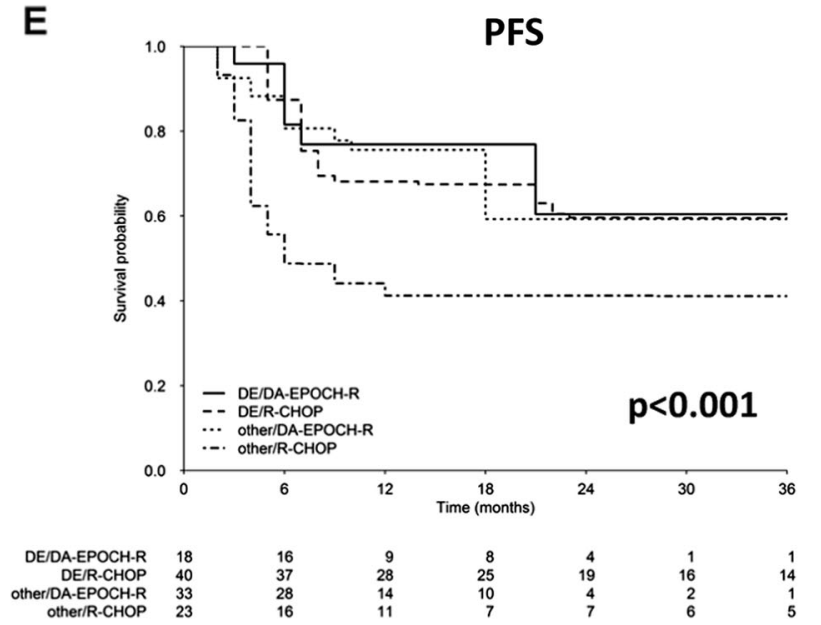

Fig. 1 Weighted Kaplan-Meier curves of progression-free survival (a) and overall survival (b) in all patients according to treatment (DAEPOCH-R or R-CHOP); Weighted Kaplan-Meier curves of progression-free survival (c) and overall survival (d) according to treatment in patients younger than 65 years. Weighted Kaplan-Meier estimates of progression-free survival according to biology (DE patients with cytogenetic alteration such as $\mathrm{SH}, \mathrm{DH} / \mathrm{TH}$, or atypical DH defined as "other" vs patients without any abnormalities defined as "DE-only") and treatment (e) 
It is true that the median follow-up for DA-EPOCH-R (20 months) cohort is shorter than R-CHOP (49 months), but recent studies showed that PFS at 24 months is a valuable surrogate end-point for OS in DLBCL patients [15]. The 2-year PFS following DA-EPOCH-R in younger patients is promising, but a prospective trial is required to confirm these findings.

In conclusion, the DA-EPOCH-R regimen is feasible in patients up to 79 years of age, but the advantage of using an intensive regimen is likely related to the dose escalation. The results of the present study suggest that intensive chemotherapy, such as DA-EPOCH-R, should be considered for patients with DE DLBCL aged less than 65 years.

Acknowledgements This study received support from Associazione Italiana contro Linfomi e Leucemie (AIL) and Fondazione Adiuvare.

\section{Compliance with ethical standards}

Conflict of interest The authors declare that they have no conflict of interest.

Open Access This article is licensed under a Creative Commons Attribution 4.0 International License, which permits use, sharing, adaptation, distribution and reproduction in any medium or format, as long as you give appropriate credit to the original author(s) and the source, provide a link to the Creative Commons license, and indicate if changes were made. The images or other third party material in this article are included in the article's Creative Commons license, unless indicated otherwise in a credit line to the material. If material is not included in the article's Creative Commons license and your intended use is not permitted by statutory regulation or exceeds the permitted use, you will need to obtain permission directly from the copyright holder. To view a copy of this license, visit http://creativecommons. org/licenses/by/4.0/.

\section{References}

1. Le Gouill S, Talmant P, Touzeau C, Moreau A, Garand R, JugeMorineau $\mathrm{N}$, et al. The clinical presentation and prognosis of diffuse large B-cell lymphoma with $\mathrm{t}(14 ; 18)$ and 8q24/c-MYC rearrangement. Haematologica. 2007;92:1335-42.

2. Niitsu N, Okamoto M, Miura I, Hirano M. Clinical features and prognosis of de novo diffuse large B-cell lymphoma with $\mathrm{t}(14 ; 18)$ and 8q24/c-MYC translocations. Leukemia. 2009;23:777-83.

3. Johnson NA, Savage KJ, Ludkovski O, Ben-Neriah S, Woods R, Steidl C, et al. Lymphomas with concurrent BCL2 and MYC translocations: the critical factors associated with survival. Blood. 2009;114:2273-9.

4. Green TM, Young KH, Visco C, Xu-Monette ZY, Orazi A, Go $\mathrm{RS}$, et al. Immunohistochemical double-hit score is a strong predictor of outcome in patients with diffuse large B-cell lymphoma treated with rituximab plus cyclophosphamide, doxorubicin, vincristine, and prednisone. J Clin Oncol. 2012;30:3460-7.

5. Hu S, Xu-Monette ZY, Tzankov A, Green T, Wu L, Balasubramanyam A, et al. MYC/BCL2 protein coexpression contributes to the inferior survival of activated B-cell subtype of diffuse large B-cell lymphoma and demonstrates high-risk gene expression signatures: a report from The International DLBCL RituximabCHOP Consortium Program. Blood. 2013;121:4021-31.

6. Perry AM, Alvarado-Bernal Y, Laurini JA, Smith LM, Slack GW, Tan KL, et al. MYC and BCL2 protein expression predicts survival in patients with diffuse large B-cell lymphoma treated with rituximab. Br J Haematol. 2014;165:382-91.

7. Rosenbaum PR, Rubin DB. Reducing bias in observational studies using subclassification on the propensity score. J Am Stat Assoc. 1984;79:516-24.

8. Swerdlow SH, Campo E, Pileri SA, Harris NL, Stein H, Siebert R, et al. The 2016 revision of the World Health Organization classification of lymphoid neoplasms. Blood. 2016;127:2375-90.

9. Wilson WH, Grossbard ML, Pittaluga S, Cole D, Pearson D, Drbohlav N, et al. Dose-adjusted EPOCH chemotherapy for untreated large B-cell lymphomas: a pharmacodynamic approach with high efficacy. Blood. 2002;99:2685-93.

10. Li S, Seegmiller AC, Lin P, Wang XJ, Miranda RN, Bhagavathi $\mathrm{S}$, et al. B-cell lymphomas with concurrent MYC and BCL2 abnormalities other than translocations behave similarly to $\mathrm{MYC} /$ BCL2 double-hit lymphomas. Mod Pathol. 2015;28:208-17.

11. Oki Y, Noorani M, Lin P, Davis RE, Neelapu SS, Ma L, et al. Double hit lymphoma: the MD Anderson Cancer Center clinical experience. Br J Haematol. 2014;166:891-901.

12. Savage KJ, Slack GW, Mottok A, Sehn LH, Villa D, Kansara R, et al. Impact of dual expression of MYC and BCL2 by immunohistochemistry on the risk of CNS relapse in DLBCL. Blood. 2016;127:2182-8.

13. Petrich AM, Gandhi M, Jovanovic B, Castillo JJ, Rajguru S, Yang DT, et al. Impact of induction regimen and stem cell transplantation on outcomes in double-hit lymphoma: a multicenter retrospective analysis. Blood. 2014;124:2354-61.

14. Landsburg DJ, Falkiewicz MK, Maly J, Blum KA, Howlett C, Feldman T, et al. Outcomes of patients with double-hit lymphoma who achieve first complete remission. J Clin Oncol. 2017;35:2260-7.

15. Maurer MJ, Habermann T, Shi Q, Schmitz N, Cunningham D. Utility of progression-free survival at 24 months (PFS24) to predict subsequent outcome for patients with diffuse large B-cell lymphoma (DLBCL) enrolled on randomized Clinical Trials: findings from a surrogate endpoint in aggressive lymphoma (SEAL) analysis of individual patient data from 5853 patients. Blood. 2016;128:3027. 